\title{
BLAST TESTING OF ENERGY ABSORBING CONNECTORS FOR BLAST RESISTANT DESIGN
}

\author{
CHARLES OSWALD \\ Protection Engineering Consultants, Texas, USA
}

\begin{abstract}
Structural components are typically designed to resist blast loads with rigid connections. An innovative approach for blast design is to support blast-loaded cladding components on a building with energy absorbing connections (EACs), which deform as they resist the dynamic reaction load from the component. The EACs and the structural component both deform dynamically to absorb the energy applied by the blast load, such that the EACs limit the peak dynamic reaction load transmitted into the supporting structure and reduce the damage to the supported component compared to traditional rigid supports. This paper discusses a series of comparable shock tube tests of precast concrete panels that are supported by EACs and by rigid supports. The panels were tested with shock loads similar to those from large high explosive threats, including tests to investigate the EAC response during the negative phase of the blast load.
\end{abstract}

Keywords: energy absorbing connections, blast loads.

\section{INTRODUCTION}

A wide variety of energy absorbing connectors have been developed and successfully used to limit the energy from earthquake-induced ground motion that is absorbed by structures [1], [2]. They have also been developed and tested for a blast loaded curtain wall system [3] and a blast loaded wall supported by a relatively weak lateral load resisting system [4]. The absorbing connections (EACs) discussed in this paper have been in development for the Bureau of Diplomatic Security at the US Department of State over several years. The development work started with a literature search and component static and dynamic testing of individual EACs [5]. It has also included development of a simplified design methodology that idealizes a component and the supporting EACs as an equivalent three degree-offreedom (3DOF) system and dynamic finite element modelling [5].

Fig. 1 shows two types of EACs that have been developed and tested. Both types use a steel EAC consisting of $3 \times 3 \times 1 / 4$ Grade 50 steel angles welded to 3/8 in thick top and bottom baseplates. The baseplates are connected to the supported component (e.g. wall panel) and to the supporting structure. This EAC is similar to previously developed ductile steel connectors for components loaded by blast and impact [4], [6], [7]. The combined EAC is a steel EAC with aluminium honeycomb material inserted between the baseplates to increase the compression capacity of the EAC. Both the steel EAC and the aluminium honeycomb material yield at a small compressive deflection (less than 5\% axial strain) and have a nearly constant resisting load (i.e. yield load) up to a large deflection (near $65 \%$ strain) when lockup or steel fracture occurs. Fig. 2 shows typical static measured load-deflection curves for each type of EAC, where axial strain is axial deflection divided by original EAC height. Initial loading is compressive, followed by tensile loading, then followed by compressive load to failure or lockup. The steel tube "stop" in the steel EAC, and the two shorter steel tube sections laterally supporting the aluminium honeycomb material in the combined EAC, both limit the maximum strain in the steel EAC to $0.65 \mathrm{in} /$ in so that the steel EAC will not fracture during peak inbound response. 


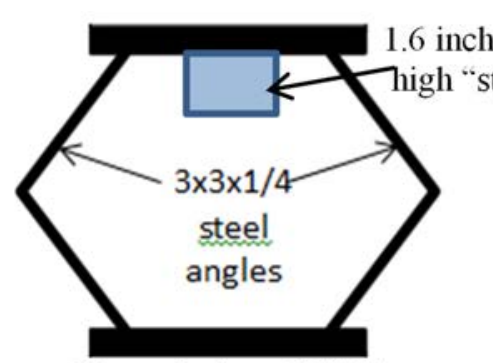

Uncrushed steel EAC

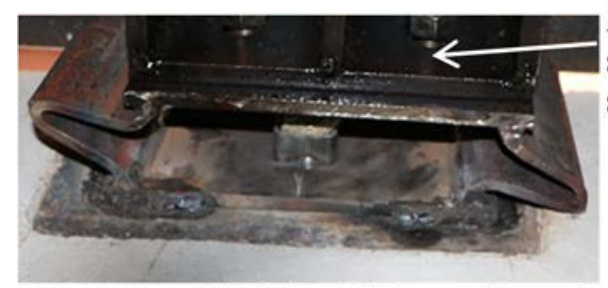

Crushed steel EAC welded to wall panel

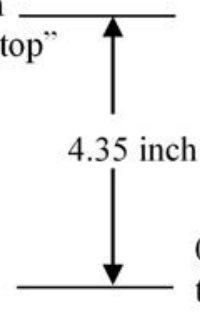

0.8 inch high tube sections

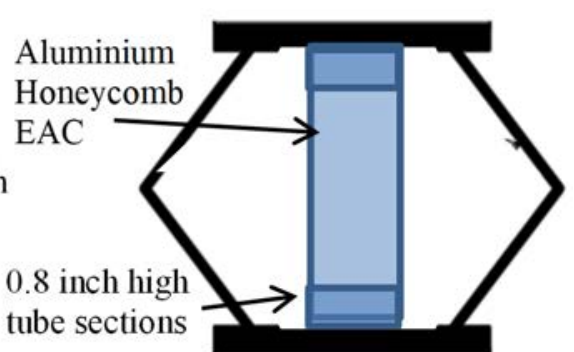

Uncrushed combined EAC

Attached to supporting structure

Incremental crushing

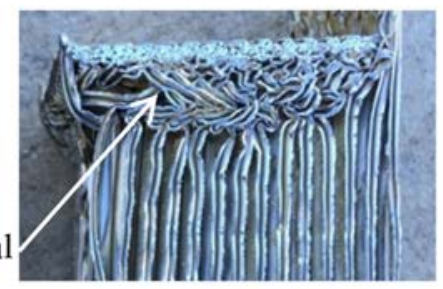

Aluminium honeycomb material

Figure 1: Two types of tested EACs.

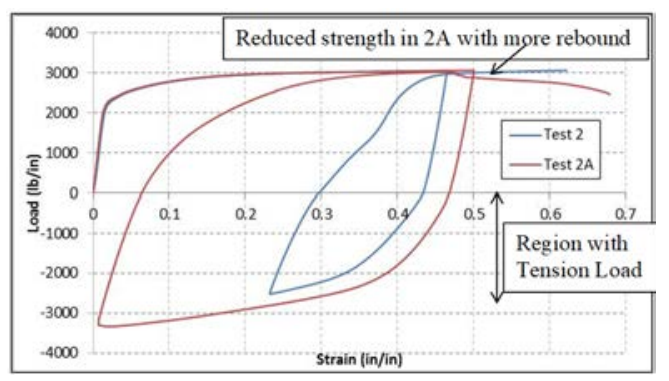

(a) Steel EAC only

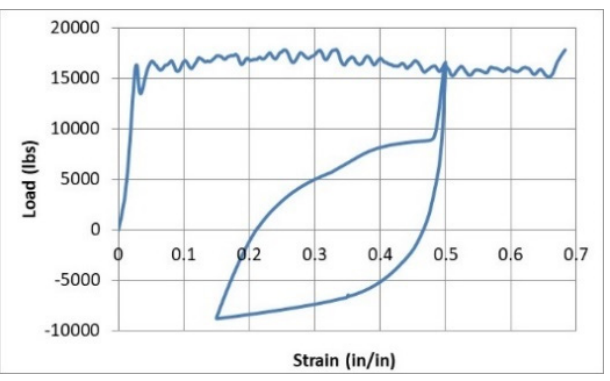

(b) Combined EAC

Figure 2: Measured static load-axial strain curves for each type of tested EACs.

The EACs absorb energy from the applied blast load by yielding ductilely as they respond to the dynamic reaction load applied by the supported façade component with a controlled, nearly constant, resisting load out to a large strain. The absorbed energy is equal to the EAC yield load multiplied by its deflection. The blast-loaded façade component supported by the EACs is designed to yield in flexure and absorb energy, so that both the EACs and supported component are designed as a system to absorb the energy applied by the blast load. If this system is optimized, the façade component can be designed with a lower strength than if it had traditional rigid supports, since it does not need to resist all the applied blast energy. Also, the yield load of the EACs can be designed to transmit a lower maximum reaction load into the supporting structure than a rigid connection. This advantage of EACs can be most important when an existing building is retrofitted with a strengthened, blast resistant façade and it is cost-prohibitive to strengthen the building's lateral load resisting system to resist the peak dynamic reaction loads from the upgraded façade attached with rigid connections. 
In a building, the EACs will be placed between the supported façade (e.g. precast panels) and the supporting structure (e.g. floor diaphragm) so that there is a lateral offset distance equal to the EAC height (i.e. dimension of EAC in the direction it deflects) of 4 to 6 inches. The façade response to blast load will initially put the EACs in compression (i.e. reducing its height), and then rebound of the façade components will put the EACs into tension. The EACs will be attached to the façade and floor diaphragm with positive connections that resist the peak tension load from the EACs. Fig. 3 shows a concept for EACs in a building.

\section{SHOCK TUBE TESTING}

Table 1 shows a total of 12 directly comparable shock tube tests that were performed on reinforced concrete panels with rigid supports and with energy absorbing connectors (EACs). There are four series of comparable tests, where the blast load and the panel construction were nearly identical within each series. Fig. 4 shows post-test photographs of comparable test panels with and without EACs. All the test panels were $8 \mathrm{ft} \times 8 \mathrm{ft}$ with thicknesses as shown in Table 1 that were supported at two locations along the top and the bottom, so that there was a $7.25 \mathrm{ft}$ center-to-center span distance between supports. Both the rigid and EAC supports were designed to act primarily as simple supports for the test panel spanning vertically. The supports were designed to prevent any tension membrane response in the test panels, so that they had only flexural response to the applied shock loads.

All the EACs for the test panels were constructed with $3 \times 3 \times 1 / 4$ Grade 50 steel angles welded to a top and bottom $3 / 8$ inch baseplate with a static yield load of $3000 \mathrm{lb} /$ in of length along the steel angles. The combined EACs had an additional static yield load equal to the cross-sectional area of the aluminium honeycomb material in compression multiplied by a compression strength of $3,700 \mathrm{lb} / \mathrm{in}^{2}$. All EACs were designed with a yield load such that they would deflect with 2.0-2.5 inches (i.e. a strain no greater than $0.65 \mathrm{in} / \mathrm{in}$ ) using the MDOF analysis method. Table 1 shows static yield loads for each EAC in terms of the steel EAC yield load followed by the aluminium honeycomb material yield load in parentheses for combined EACs. Therefore, the total static yield load of combined EACs in Table 1 is the sum of both yield loads.

All the applied shock loads rose immediately to the peak pressure and then decayed in approximately a linear manner to ambient pressure, where the integral of the measured pressure vs. time curve was equal to the impulses shown in Table 1. Also, the precast panel midspan deflection history and the dynamic load history at each of the four support points (rigid supports or EACs) for the panel were measured during each test, as well as the

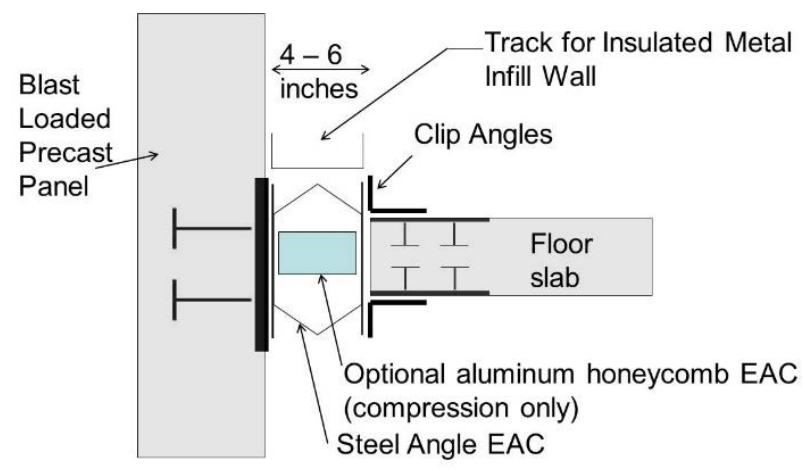

Figure 3: Conceptual placement of EAC in building. 


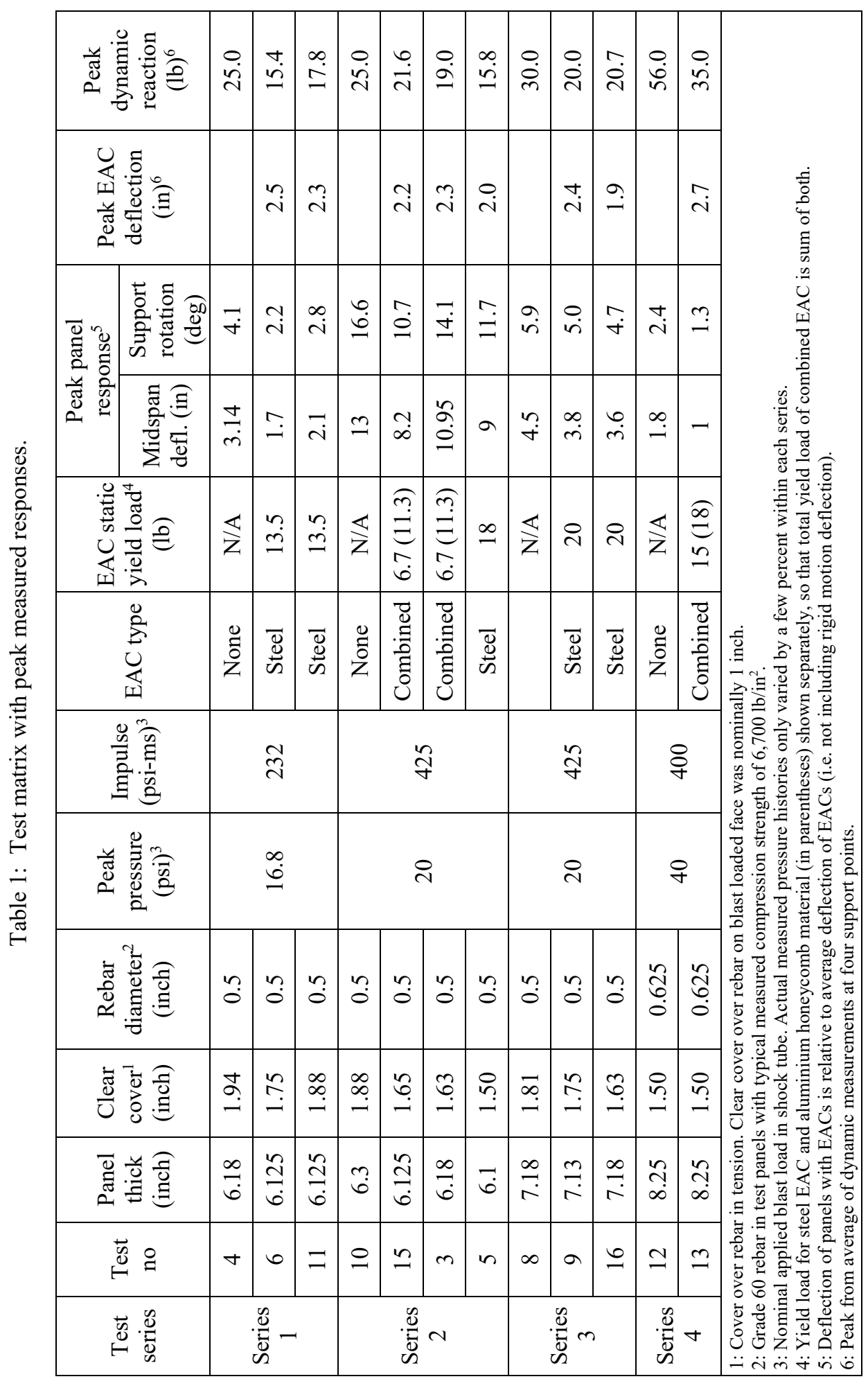




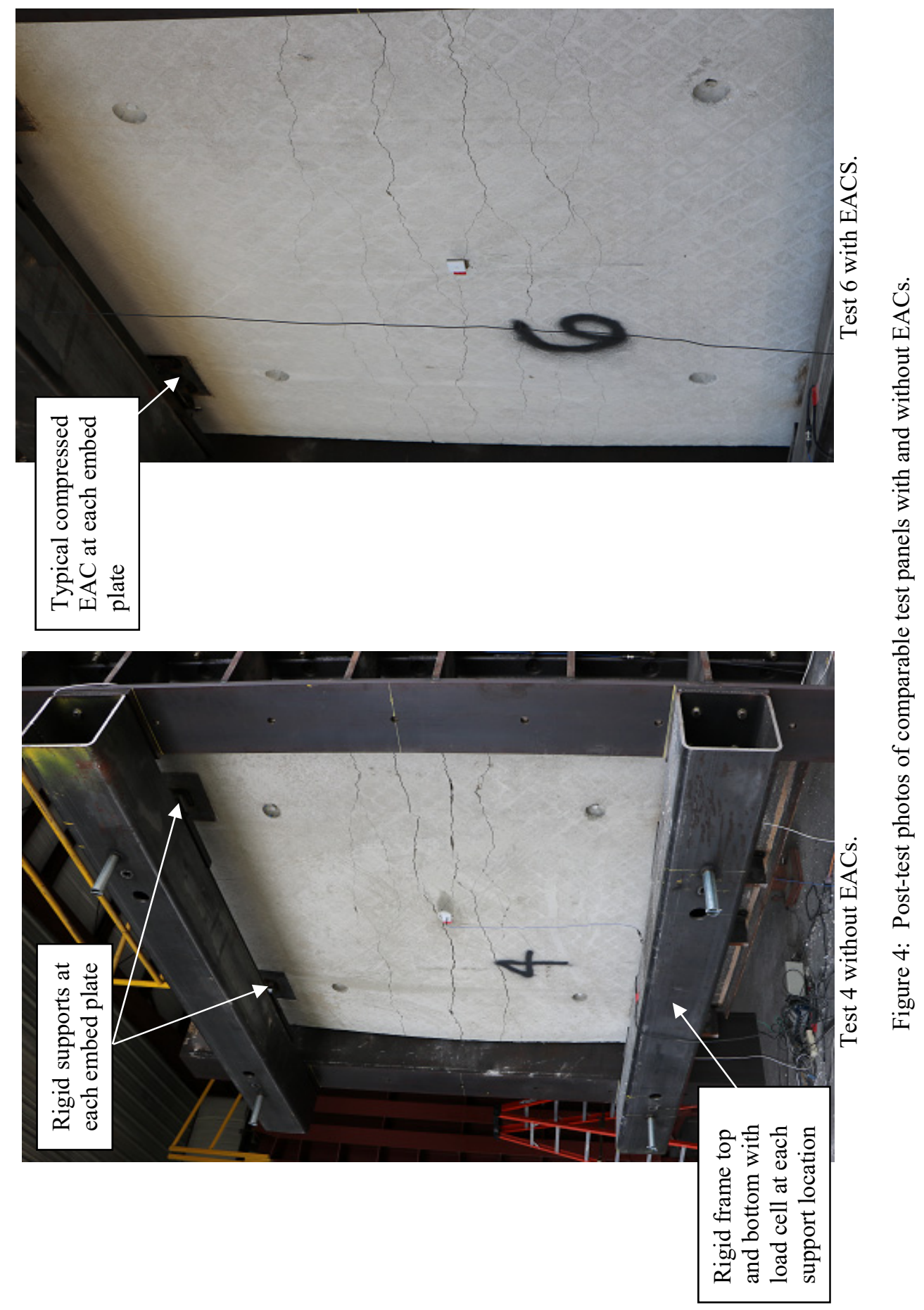


deflection history at each EAC. shows peak measured results from each test, where the peak reaction loads and EAC deflections are based on the average of the measurements at four locations (i.e. support points) during each test. For test panels with EACs, the peak panel midspan deflection in the table is relative to the average deflection of the four EACs supporting the test panel. This relative deflection is the deflection causing damage to the test panel (i.e. not including rigid motion deflection) that is comparable to the peak deflection of panels without EACs.

The tests with rigid supports had a 5 inch steel plate (matching the overall EAC dimension) in place of the EACs, with a 3 inch $\times 1$ inch cross section, welded to the embed plate and bolted to the support tube. The test panels were directly supported by either four 5 inch rigid steel plate, or four identical EACs, and both types of support were attached with two bolts to the $4 \times 4 \times 0.5$ support tube shown in Fig. 5. There was a support tube at the top and at the bottom of the test panels. Each support tube was laterally supported by the large rigid tubes shown in Fig. 4, with a load cell at the center of each support point bolted between the support tube and large rigid tube (see Fig. 5). Therefore, the lateral reaction load went directly through the support tubes at each support point into the load cells that were supported by the rigid tubes. The dead weight of the support tubes was supported by an angle welded to the rigid tubes, as shown in Fig. 5. Fig. 5 also shows at typical LVDT at each support that measured the EAC deflection history. Additionally, Fig. 5 shows combined EACs for Test Panel 13 before and after testing of the panel.

Fig. 6 shows typical measured average reaction loads for comparable tests without and with EACs (i.e. Tests 4 and 6) and measured deflection histories at each EAC in Test 6 and at midspan. The total midspan deflection of Test Panel 6 is equal to the sum of the relative midspan deflection history shown in Fig. 6 plus the average of the EAC deflection histories shown in the figure. The plastic deformed shapes of the EACs along their length (i.e. in their direction along the span of the test panel) showed that they deflected to match the support rotation of the test panels, where the edge of the EACs nearest midspan of the test panels had the largest deflection and the opposite edge had the least deflection. The measured EAC deflections in Table 1 are at the center of the EAC length.

In addition to the tests shown in Table 1, three test panels as summarized in Table 2 were retested in a reverse manner; the panels were turned around in the shock tube so the applied load put the previously compressed EACs into tension. The purpose of these tests was to apply shock loads representing the negative phase of a high explosive blast load that would apply tension to the EACs as they rebounded after compression by the initial positive phase of the blast load.

In the first of these tests, Test Panel 13 was loaded with a conservatively large shock load and both of the EACs along the top of the test panel fractured during their tensile response. Two more tests panels were retested in a similar manner with lower blast loads, which more realistically represented the negative phase blast load from high explosive threats that could be resisted by the test panels. None of the EACs failed in these two tests. Fig. 7 shows one of the EACs that failed during the reverse "rebound" loading. Many of the EACs had an asymmetric deflection as illustrated in Fig. 7, associated with a small lateral deflection in the plane of the test panel.

\section{ANALYSIS OF TEST DATA}

Table 3 shows the effect of EACs, compared to rigid supports, on the peak measured response of test panels from each tests series in Table 1. As expected, the use of EACs significantly reduces the peak midspan panel deflections and peak dynamic reaction loads compared to 

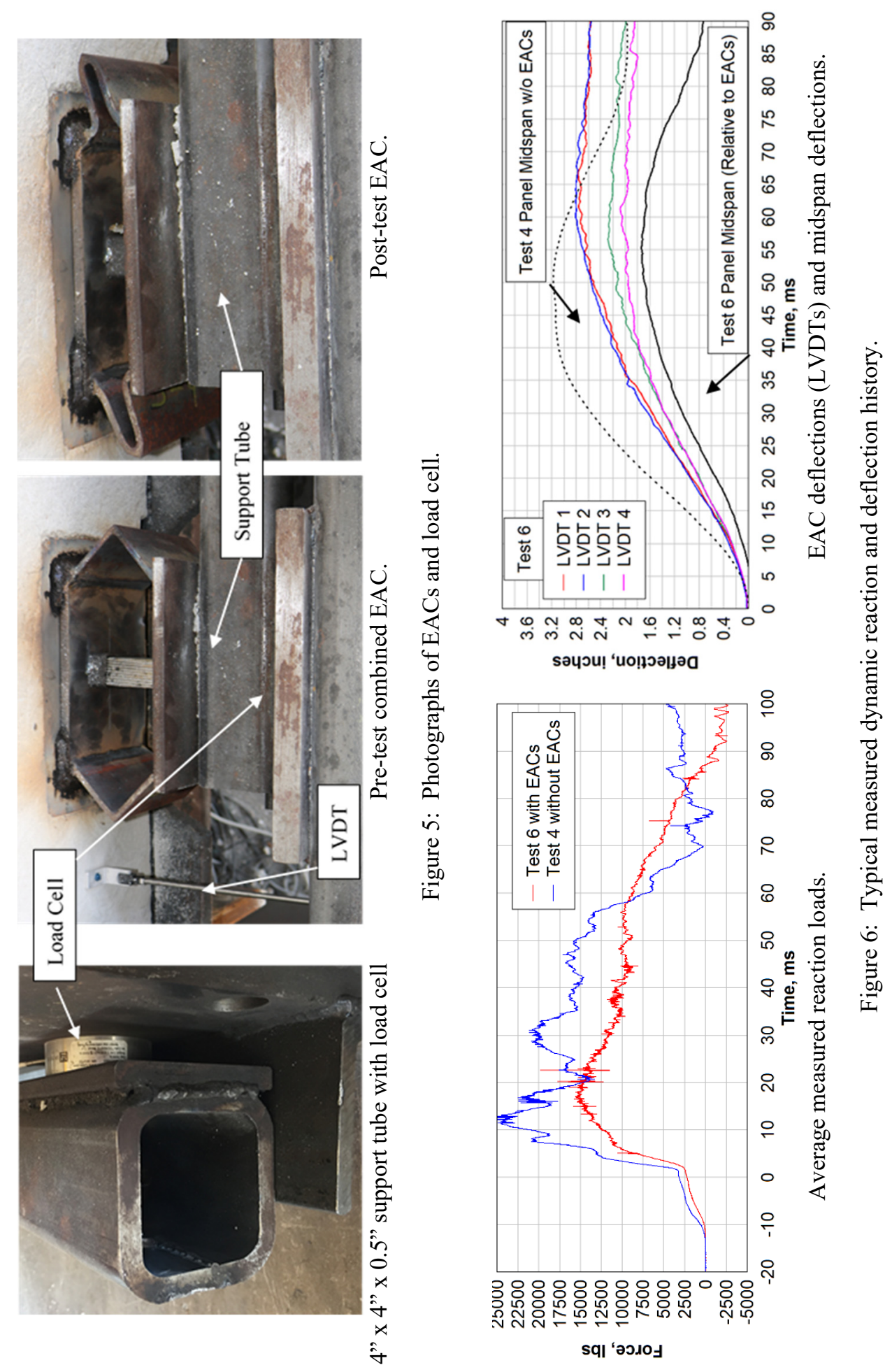
Table 2: Reverse load tests on EACs.

\begin{tabular}{|c|c|c|c|c|c|c|}
\hline \multirow{2}{*}{ Test panel no. } & \multicolumn{2}{|c|}{ Applied shock load } & \multicolumn{2}{c|}{$\begin{array}{c}\text { Dynamic tensile } \\
\text { deflection (inch) }\end{array}$} & \multicolumn{2}{|c|}{$\begin{array}{c}\text { Plastic tensile } \\
\text { deflection (inch) }\end{array}$} \\
\cline { 2 - 7 } & $\begin{array}{c}\text { Peak pressure } \\
\text { (psi) }\end{array}$ & $\begin{array}{c}\text { Impulse } \\
\text { (psi-ms) }\end{array}$ & Peak & Average & Peak & Average \\
\hline 13 & 7.3 & 333 & 0.33 & 0.3 & \multicolumn{2}{|c|}{ Failure } \\
\hline 11 & 3.3 & 146 & 0.3 & 0.2 & 0.3 & 0.25 \\
\hline 16 & 4.2 & 187 & 0.17 & 0.14 & 0.34 & 0.11 \\
\hline
\end{tabular}

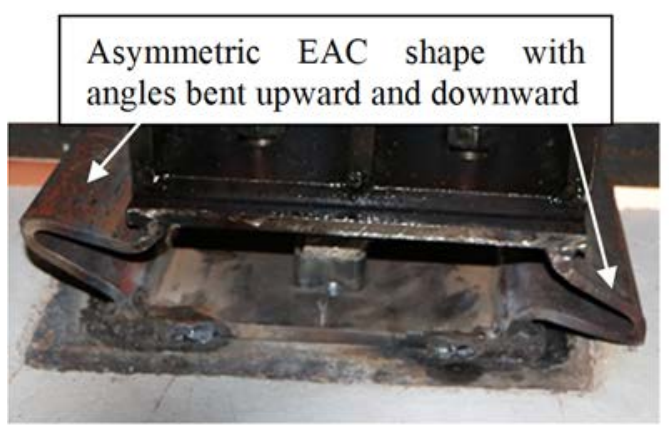

EAC prior to rebound test

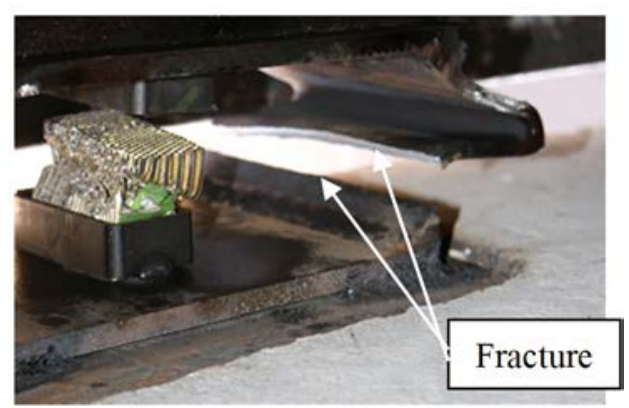

Post-test EAC with fracture.

Figure 7: Failed EAC during reverse blast load test.

similar shock tube tests on similar panels with rigid supports. The peak reaction loads from tests with EACs, which are equal to the peak dynamic yield load of the EACs, were approximately two-thirds of the peak dynamic reaction force of comparable blast-loaded test panels with rigid supports. This ratio could be somewhat smaller if the EACs were designed to undergo a larger peak deflection. The peak relative midspan deflections of test panels with EACs were $20-40 \%$ less than the peak midspan deflections of comparable blast-loaded test panels with rigid supports. The precast panel damage levels of comparable test panels with and without EACs differed in a similar manner, where the damage levels were determined from criteria based on a large database of blast tested precast concrete panels [8]. Based on the relatively uniform amount of peak EAC response (i.e. between 2.0 and 2.5 inches), the EACs were expected to have the largest relative effect on panels with the smaller deflections (i.e. the energy absorbed by the EAC as it deflected was a larger compared to energy absorbed by the flexural response if the test panel for these cases). This is generally true in Table 2 , except for Test Series 2.

Another area of interest during testing was the repeatability of measured response of similar blast-loaded test panels with similar EACs. The test panels in Series 1, 2, and 3 in Table 2 all had very similar shock loads, panel construction, and EAC yield loads. The peak measured panel midspan deflections, average EAC deflections, and dynamic reactions within each of the three groups (9 comparisons) differed by a maximum of $21 \%$ except for the midspan panel deflections for Series 2 with a maximum $28 \%$ difference. These differences are within the range of response expected between similar test panels with rigid supports during blast testing. This indicates that these tests on precast panels supported by EACs are 
Table 3: Effect of EACs on peak test panel response.

\begin{tabular}{|c|c|c|c|c|c|c|c|}
\hline \multirow[t]{2}{*}{ Series } & \multirow{2}{*}{$\begin{array}{c}\text { Nominal } \\
\text { panel } \\
\text { thickness } \\
\text { (inches) }\end{array}$} & \multicolumn{2}{|c|}{ Applied blast load } & \multicolumn{2}{|c|}{$\begin{array}{c}\text { Reduction factor in } \\
\text { peak response caused } \\
\text { by EACs }{ }^{1}\end{array}$} & \multicolumn{2}{|c|}{ Damage level } \\
\hline & & $\begin{array}{c}\text { Peak pressure } \\
\text { (psi) }\end{array}$ & $\begin{array}{l}\text { Impulse } \\
\text { (psi-ms) }\end{array}$ & $\begin{array}{c}\text { Panel } \\
\text { deflection }\end{array}$ & $\begin{array}{c}\text { Reaction } \\
\text { force }\end{array}$ & $\begin{array}{l}\text { Without } \\
\text { EACs }\end{array}$ & $\begin{array}{l}\text { With } \\
\text { EACs }\end{array}$ \\
\hline 1 & 6 & 16.8 & 232 & 0.60 & 0.65 & $\begin{array}{l}\text { Moderate- } \\
\text { high }\end{array}$ & $\begin{array}{l}\text { Moderate- } \\
\text { low }\end{array}$ \\
\hline 2 & 6 & 20 & 425 & 0.72 & 0.76 & $\begin{array}{l}\text { Insipient } \\
\text { failure }\end{array}$ & Heavy \\
\hline 3 & 7 & 20 & 425 & 0.82 & 0.68 & Heavy & Moderate \\
\hline 4 & 8 & 40 & 400 & 0.56 & 0.63 & $\begin{array}{c}\text { Low- } \\
\text { moderate }\end{array}$ & Low \\
\hline
\end{tabular}

as repeatable as blast tests on components with rigid supports. Also, the measured maximum deflections of the EACs, ranging from 1.9-2.7 inches, were within the expected range given that the test parameters were calculated to cause EAC deflections between 2.0 and 2.5 inches.

An unexpected trend in the test data was that the top EACs had significantly less peak measured deflection and post-test plastic deflection compared to the bottom EACs (at least $40 \%$ less) in most of the Series 1 and Series 2 tests in Table 1. This trend did not occur in the Series 3 and 4 tests. The primary difference between the test panels in these two sets of series is that all the test panels in Series 1 and Series 2 were only 6 inches thick, whereas the test panels in Series 3 and 4 were 7 inches and 8 inches thick. Fig. 8 shows the average measured force vs. deflection curve at the top EACs and the bottom EACs in Test 5, which was generally representative for the Series 1 and 2, and in Test 16, which was generally representative for the Series 3 and 4 tests. These load-deflection curves were constructed from the measured load cell and LVDT measurements at each time step.

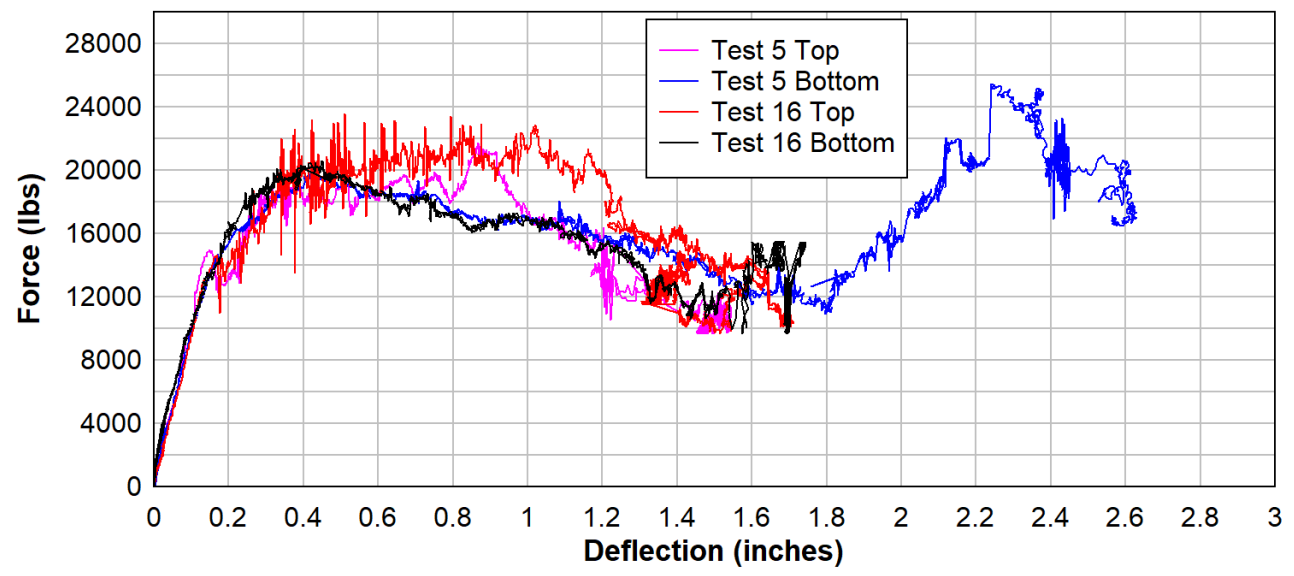

Figure 8: Average of force vs. deflection for EACs at top and bottom supports. 
This trend is currently being investigated with dynamic finite element analyses of the test panels. Fig. 9 shows typical cross sections through the top and bottom supports for the test panel at maximum calculated panel response to the applied shock load, showing the EAC, support tube, the angle supporting the weight of the support tube, and load cell bolted between the support tube and rigid support. The EAC is multi-colored between two yellow baseplates, as shown in cross section A-A. The finite element results indicate that there were not fully symmetric support conditions at the top and bottom of the test panels. The bottom plates of the EACs were allowed to rotate more at the top of the test panels than at the bottom of test panels due to less rotational restraint provided by the support tube. This difference may contribute to the differing amounts of measured EAC deflection at the top and bottom of the test panel. Also, the load cells function best when they remain in full contact with the loading surface and support surface, which occurred more at the bottom support than at the top support. Fig. 9 also shows how the EACs at the top and bottom supports deformed more along their length on the edge closer to the midspan of the test panels, which agrees with observations of the tested EACs.

\section{SUMMARY AND CONCLUSIONS}

This paper discusses shock tube tests on reinforced concrete precast panels supported by energy absorbing connectors (EACs) consisting of a steel EAC constructed with $3 \times 3 \times 1 / 4$ Grade 50 steel angles welded to top and bottom plates and combined EACs that also included aluminium honeycomb material placed between the top and bottom plates of the steel EACs. Precast panels were tested in four series of tests, where similar test panels with similar applied shock loads were tested with EACs and with rigid supports in each test series. The measured maximum deflections and peak reaction forces from comparable tests in each series showed that the EACs reduced the peak response and the peak reaction forces from the test panels compared to rigid supports. The peak panel deflections were reduced by $20-40 \%$, where the reduction was generally highest for test panels that had lower peak deflections since the energy absorbed the EACs was a larger proportion of the energy absorbed by the flexural response of these test panels. The peak reaction force was also reduced by $25-40 \%$, where the reduction was primarily a function of the design yield load for the EACs. The EACs were designed to deflect from 2.0-2.5 inches in the tests panels, which was generally consistent with the maximum measured EAC displacements in the tests that varied from 1.9-2.7 inches. Also, similar test panels with similar shock loading and EAC yield loads had similar measured response (i.e. almost all with $21 \%$ ), so the test results were fairly repeatable.
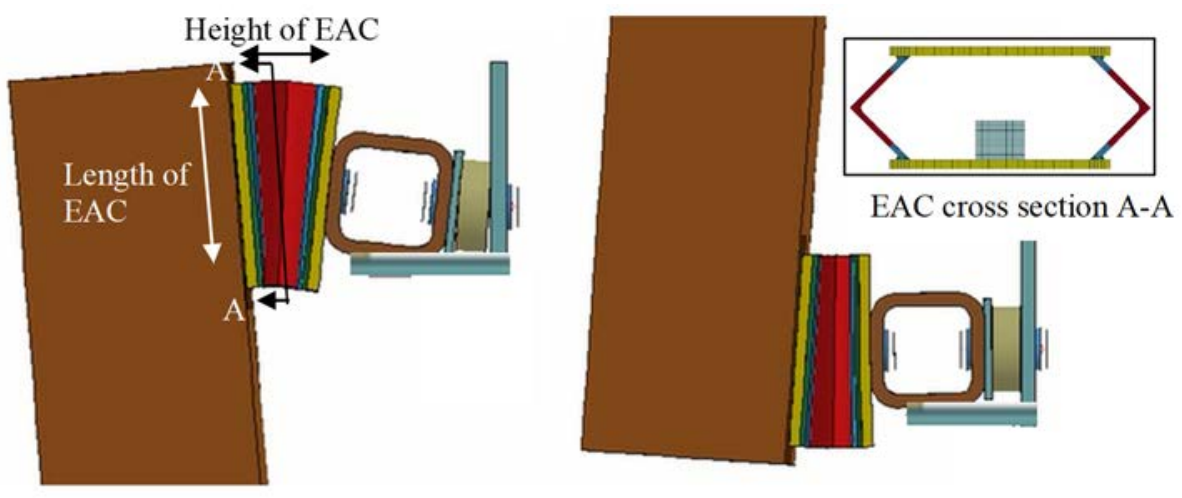

Figure 9: Different calculated rotations of top and bottom support tubes. 


\section{REFERENCES}

[1] Torunbalci, N., Seismic isolation and energy dissipating systems in earthquake resistant design. 13th World Conference on Earthquake Engineering, Vancouver, BC, Canada, Aug. 2004.

[2] Buckle, I., Passive control of structures for seismic loads. 12th World Conference on Earthquake Engineering, Auckland, New Zealand, 2000.

[3] Morison, C., Zobec, M., Lori, G. \& Mocibo, D., Design and experimental validation of dissipative bracket supports for curtain wall blast enhancement. Proceedings of the 17th ISIEMS Conference, Bad Neuenahr, Germany, October 16-20, 2017.

[4] Whitney, M., Blast damage mitigation using reinforced concrete panels and energy absorbing connectors. Proceedings of the 27th DoD Explosives Safety Seminar, Las Vegas, NV, Aug. 1996.

[5] Oswald, C.J. \& Bazan, M., Energy absorbing connectors for blast resistant design. Proceedings of the 39th IABSE Symposium, Vancouver, BC, Canada, Sep. 2017.

[6] Lavarnway, D., Evaluating the use of ductile envelope connectors for improved blast protection of buildings. Master's thesis, Case Western Reserve University, May 2013.

[7] Olabi, A.G., Morris, E., Hashmi, M.S.J. \& Gilchrist, M.D., Optimized design of nested circular tube energy absorbers under lateral impact loading. International Journal of Impact Engineering, 35(1), 2008.

[8] Oswald, C.J. \& Bazan, M., Performance and blast design for non-load bearing precast concrete panels. Proceedings from the SEI Congress, Boston, MA, 2104. 